\title{
Leadership Styles in the Maintenance Industry of UAE: A Focus Group Analysis
}

\author{
Prof. Dr. Hummayoun Naeem \\ Muhammad Farooq Azam \\ Department of Management Sciences, SZABIST, \\ Dubai International Academic City, UAE
}

doi: 10.19044/esj.2017.v13n7p53 URL:http://dx.doi.org/10.19044/esj.2017.v13n7p53

\begin{abstract}
The primary objective of this qualitative research is to identify and study various leadership styles in the maintenance industry of UAE. The researcher used focus group as a method of data collection. 8 senior officers from the various reputed maintenance companies were invited for the deliberation on the leadership styles being practiced in the various management hierarchies of such companies. The researcher also investigated success level of various leadership styles in terms of employee motivation and moral. The researcher guided the Focus Group Members' discussion around these areas, took notes, and finally complied all the views in a report format. Study revealed that Top level management practicing autocratic style of leadership that is not yielding the desired results of higher motivation level and subordinates are also not really happy with it. Targets and being achieved but corporate citizenship feel is missing in the subordinates. Middle level management is practicing almost all types of leadership styles but team leadership is most commonly used by middle level management, subordinates are generally happy with it. Lower level management using autocratic leadership style in order to control the field staff; however field staff never felt happy with it as they feel bad when always engineers / supervisors imposing their decisions on them and being the work floor workers, their suggestions are not taken care of.
\end{abstract}

Keywords: Leadership Styles, Maintenance Industry, UAE, Focus Group, Analysis

\section{Introduction}

Leadership is defined as an approach that causes change in individuals and social systems. In its ideal form, it creates valuable and positive change in the followers with the end goal of developing followers 
into leaders. Enacted in its authentic form, transformational leadership enhances the motivation, morale and performance of followers through a variety of mechanisms (Wang et al. 2005).

These include connecting the follower's sense of identity and self to the mission and the collective identity of the organization; being a role model for followers that inspires them; challenging followers take greater ownership for their work, and understanding the strengths and weaknesses of followers, so the leader can align followers with tasks that optimize their performance.

The importance of leadership for effective safety management has been the focus of research in industry for a number of years, especially in energy and manufacturing sectors. In contrast, very little research into leadership and safety has been carried out in medical settings. A selective review of the industrial safety literature for leadership research with possible applications in health care was undertaken (Vivek, 2016).

Research findings (Toor and Afori, 2008) indicate the importance of participative, transformational styles for safety performance at all levels of management. Its importance is increasing due to rising number of equipments, systems, machineries and infrastructure. Since the industrial revolution, devices, equipment, machinery and structures have grown increasingly complex, requiring a host of personnel, vocations and related systems needed to maintain them. In different countries billions of dollars are being spent annually on maintenance and operations alone. Maintenance is to ensure a unit is fit for purpose, with maximum availability at minimum costs. Last decades of 20th century have seen increasing research in the area of beneficial non task behavior of employees.

\section{Theoretical Background}

Leadership theory was developed in the late 20th century by Burns (1978) in his analysis of political leaders. Prior to this time, much attention had been given to the examination of the approaches of leaders who successfully transformed organizations. Burns (1978) characterized transformational leadership as that which "occurs when one or more persons engage with others in such a way that leaders and followers raise one another to higher levels of motivation and morality".

He believed that transformational leadership could raise followers from a lower level to a higher level of needs which agrees with Maslow's (1954) hierarchy of needs Bass (1985) refined and expanded Burns' leadership theory. He further said that a leader is one who motivates us to do more than we originally expected to do. He further agreed with Maslow that humans follow them following hierarchy of need 
Self Actualization

Self Esteem

Social Needs

Security Needs

Physical needs for survival

Humans keep struggling as per this hierarchy of needs. Naeem et al (2011) presented a pain-pleasure theory of motivation while following the Abraham Maslow school of through. Bass (1985) further argued that this motivation could be achieved by raising the awareness level about the importance of outcomes and ways to reach them. Bass also said that leaders encourage followers to go beyond self-interest for the good of the team or the organization.

According to Aarons (2006), Leadership is associated with organizational and staff performance. Personal and organizational behavior related to leadership demands a more candid look at the leadership styles which may have a positive or negative impact on these two variables.

\section{Building Maintenance:}

There is no building that is maintenance free, so every structure required maintenance in order to extend its life, the same exposes to the various element causing building materials to witness wear and tear. Periodic inspection can help to identify problems early and maintenance companies can take prior action to rectify it. We can extend the life of buildings and equipment's by practicing this, followings are the benefits of maintenance.

- $\quad$ Assets will perform better

- $\quad$ Their life will be extended

- $\quad$ Operating costs will be reduced

- Users and community members will have a more favourable perception of the building and its owner

- Whenever there is some problem in the machines, the same may be fixed immediately without causing further damage to the system.

- $\quad$ Regular service of the already fixed machines

- $\quad$ Taking care of the janitorial services also comes under the operations and maintenance industry.

- $\quad$ Industrially set standards are applied in this regard

- Maintaining air conditioning services is also part of the maintenance industry

- $\quad$ Painting and wall papers have their significant place in this demanding industry 


\section{Problem Statement}

Keeping in view the above discussion the researcher planned to analyse the phenomenon of leadership styles in the maintenance industry of UAE.

\section{Objective Of The Study}

The main objective of this study is to analyse leadership styles being used at various management levels in the maintenance industry of UAE and reaction of subordinates to such styles of leadership.

\section{Significance of the Research}

The findings of the study may be of great use to the Maintenance industry especially the companies located in UAE as the companies may incorporate the findings of the study in their daily operations to improve their working.

\section{Scope of the Research}

The research is limited to the study of leadership styles at various management levels within the maintenance industry of UAE.

\section{Literature Review}

Why leadership styles matter a lot for the organizations? The query was handled by Mauri (2017) in his research paper "Why leadership styles matter", The investigation concluded that target achievement is largely dependent upon the leadership styles. Various leadership styles have their own impact on the employee commitment and motivation. The same phenomenon was studied and endorsed by Yahaya and Ebrahim (2016).

Leaders inspire employees to achieve a certain vision for themselves, which often makes work more meaningful. Intellectual stimulation involves engaging the rationality of subordinates, getting them to challenge their assumptions and to think about old problems in new ways. Intellectually stimulating leaders may also empower their followers to become involved in decision-making and encourage them to voice their opinions (Barling et al., 2011).

Individualized consideration deals with treating employees as individuals and helping them to meet their needs However, systematic research into the nature and effects on transformational leadership in different work organizations seems to have taken firm roots following the work of Burns (1978), who distinguished two forms of leaders, that is, transactional and transformational leaders. Samuel et al. (2007) found in research that according to Burns, the main distinction and the central feature 
of transformational and transactional leadership is based on the process by which leaders motivate followers or how leaders appeal to the followers' values and emotions. Leadership motivates followers by appealing to their self-interest and it is based on exchange relationship, whereby followers compliance is exchanged for expected rewards (Pedkoff, 2014).

As discussed by Smith (1989), the situational leadership model states that," contrast between the adequacy and ineffectualness of the four leadership styles is the appropriateness of the leader's behaviour to the specific circumstance in which it is utilized". Effective leaders ought to be adaptable and can change their styles as followers and situations change over time in workplace. 'Situational leadership contends that in order to be successful managers we need to adjust our styles, according to the maturity of our people to carry out the task they are working on (Mark 1997).

Situational leadership model demonstrate that if the right style is utilized to the lower-status adherents, then they will develop and become stronger in their capacity and ability to perform and confidence. According to Hersey (2009) "situational leadership model is about being more effective as a leader".

In contrast to transactional leadership, transformational leadership entails raising the level of motivation of their followers beyond exchange values and thus achieves a higher level of performance and followers selfactualization. Burns (1978) considered transformational and transactional leadership as opposite ends of the transactional and transformational leadership effects. Toor and Afori (2008) concluded in their research that Importance of leadership in construction projects in unquestionable. As the industry is going global and projects are increasingly complex, leaders have more important role to play for the sustained success of their projects and organizations they serve and people they lead. Leadership has always mattered and its significance in the contemporary business world is more than ever before. Research on the subject can make a valuable contribution to the efforts to enhance the performance of the industry (Bass, 1985).

David and Kilner (2014) investigated leadership styles used by senior medical leaders, influence their subordinates and has lots of implications for leadership development. Higher productivity levels were found positively correlated with various leadership styles. The recent increase in research on this area, as indicated by the increased frequency of the papers reviewed in this study, and exemplified by the formation of an argument is encouraging. At this juncture in the development of the field, it is important that the research work that has been done in order to identify the ways and means of making progress in the field in future leadership domain (Bass, 1985). He further found that transformational leadership was 
positively related to altruism and compliance components of organizational citizenship behavior.

As already mentioned, there is actually a very little evidence about the effects of transformational school leadership on teachers' job satisfaction, organizational commitment, and organizational citizenship behavior in primary schools in developing countries. Gundersen, Hellesoy, and Raeder (2012) studied leadership effectiveness in international project teams facing dynamic work environments (Ogbonna \& Harris, 2016). An examination of the literature in the fields of organizational culture and leadership finds that the two areas have been independently linked to organizational performance.

For example, researchers have examined the links between leadership styles and performance Transformational leaders inspire followers to accomplish more by concentrating on the follower's values and helping the follower align these values with the values of the organization (Given, 2008). Some past studies suggest that leadership has always mattered and its significance in the contemporary business world is more than ever before. Research on the subject can make a valuable contribution to the efforts to enhance the performance of the industry (Toor and Ofori, 2008). Transformational leadership is based upon the fact that a leader can motivate followers to higher level of productivity (Chaudhary, Kuma and Philip, 2015).

\section{Synthesis of the Literature Review}

The studies reviewed for this research, are mostly empirical in nature, hypothesis based, having cause and effect relationships. The variable of leadership was measured and tested through a structured and quantitative approach. Studies are mostly addressing the impact of leadership on a variety of the corporate scenario. The intensive and extensive literature survey indicates a visible gap in the body of knowledge, when it comes to qualitative researches. Qualitative researches provide foundation for further empirical studies. By making an effective use of this visible gap, the researcher planned to analyse various leadership styles in the maintenance industry of UAE. Assuming, that the study will fill the knowledge gap and will be welcomed by the leadership practitioners and maintenance industry officials.

\section{Research Methodology}

Main objective of this chapter is to highlight the salient features of research methodology used for the completion of this research. This chapter provides details about the research methodology that was used in research to complete this research project. In this part the researcher discussed the definition of focus group research methodology, choosing focus group as 
methodology and collection of data and its tools used during data collection. Initially, the researcher had a plan to conduct an empirical bi-variate analysis. Questionnaires measuring transformational leadership and corporate citizenship behaviour were floated but the response from the industry was very poor. Managers were hesitant in extending their cooperation for the study. That made researcher to change the methodology from empirical bi-variate analysis to Focus Group discussion based qualitative research.

\section{Population Details}

Focus Group members were selected for discussion, were the officers working for the 5 leading maintenance companies of UAE namely. Company names have not been disclosed for confidentiality reasons.

\section{Data Collection}

Focus group research methodology applied method to collect data. All group members have been identified based on their experiences throughout the maintenance industry. Focus group is a part of qualitative data collection technique based on notes and audio recordings made during focus group discussion sessions collectively. The researcher had this discussion sessions by meeting with them personally for 30 minutes to 45 minutes on a cup of tea at nearby cafes and restaurants on different dates in the month of January 2017.Researcher prepared the list of points for the discussion viewing the objectives and problem statement of the research. During the focus group discussion the developed tool, which was interview guide, was used. On the basis of above tool, the researcher reviewed and concludes the notes taken during discussion in a logical manner and presented in this research.

\section{Instrumentation and Discussion}

- $\quad$ Nature of leadership in the maintenance industry

- Various Types of Leadership Being Practiced in the Maintenance industry Indentified through Focus Group discuss

- Various Types of Management Levels / Hierarchies in the Maintenance industry Indentified through Focus Group discussion

- Different types of leadership being practiced in the Maintenance industry Indentified through Focus Group discussion

- $\quad$ Different types of leadership being practiced in the Maintenance industry Indentified through Focus Group discussion 


\section{Analysis Plan}

On the basis of above tools, the researcher reviewed and concludes the notes taken during discussion in logical manner and presented in this research.

\section{Reliability and Validity of the Data}

Various statistical approaches are available for quantitative researches such as Cronbach Alpha reliability analysis through the application of SPSS. But in qualitative research, the issue of reliability and validity is challenging. The researcher handed this issue through the following measures:

- $\quad$ The researcher kept guiding the discussion towards the agenda points design for deliberations.

- $\quad$ Notes were being taken as the discussion was in progress.

- Whenever the researcher felt that there is some deviation from the core topic, the researcher interfered and directed the discussants towards the core topic of the study.

- At the compilation stage, the researcher ensure that the entire discussion is focusing the issue in question i.e. leadership styles and reaction of employees or subordinates towards that.

\section{Findings of the Study}

Based on the focus group decision, following findings of the study were generated.

\section{Leadership styles}

Below mentioned types of leadership were identified by floating the question to all the participants of the focus group that what are the various styles of leadership, identified in the maintenance industry of UAE. The discussants reported the following styles of leadership:

- $\quad$ Autocratic Leadership

- $\quad$ Democratic Leadership

- $\quad$ Strategic Leadership style

- Transformational Leadership

- Team Leadership

- $\quad$ Cross cultural Leadership

- $\quad$ Facilitative Leadership

- $\quad$ Laissez- Faire Leadership

- $\quad$ Transactional Leader ship

- $\quad$ Charismatic Leadership

- Visionary Leadership 


\section{Levels of management:} discussion:

Various levels of management identified through focus group

- $\quad$ Top Level Management

- $\quad$ Middle Management

- $\quad$ Bottom Level Management

\section{Top Level Management in Maintenance Industry:}

The top level management emphasizes on defining long term strategy, financial decisions, strategic alliances and to manage stakeholders, they look at the bigger picture of the business.

\section{Middle Level Management:}

Middle Level managers set their departments goals and responsible for decision making for their relevant departments, they would like to get monthly or weekly reports from their department to measure the performance and to take corrective action accordingly

There are four typical functional areas are as mentioned below for maintenance industry.

- Accounting

- Human resource

- Operations

- $\quad$ Business development

\section{Bottom Level management:}

In maintenance industry Engineers and Supervisors are under lower level management as they are the immediate boss of the workers, the workers follow their instructions, guidance, encouragement etc.

\section{Leadership style used in various levels of management and reactions of the subordinates.}

All participant agreed to discuss top level management that what all style they use in maintenance industry. Majority was agreed that top management uses autocratic style of leadership in maintenance industry, as they individually want to control all decisions and little contribution from rest of the team, and they rarely agree to take advices from followers.

Also they discussed the impact of this style on the subordinates, subordinates feel that they have no authority to take decisions and demoralized other employees at the same time, however there is another class of subordinates those who are happy with this and said that it is good that we don't have any responsibility, as all decisions are being taken by the 
top level management so in case of any failure of the project, will be the responsibility of the top leaders.. So the entire responsibility lies with the top management.

Majority of the participants said that in this scenario, they feel that their skills are not being used and they have no authority or right to participate in decision making and this is very much like one man show. They discussed that if there are no brain storming there are more chances to that project will fail, as more ideas can be generated with brain storming and risk can be eliminated, this practise will share the responsibilities. But overall, subordinates were not seem to be happy with this type of leadership style in which they are not being involved.

Some of them also discussed that some times, top management uses different type of leadership styles according to the situation e.g. democratic leadership style or strategic leadership style. Then questioned asked from all that what if top level management starts working with subordinates to identify the required changes and then create a vision to provide guidance through inspiration.

Almost all participants were happy with this mentioning that then top level management will get to know the ground realities and can support us in a better way to achieve organizational goal, and this what transformational leadership is all about.

One of the discussants quoted a real example of the autocratic leadership and top level management; one of the company listed above named XYZ Facilities Management is badly effected with autocratic leadership style, it is a semi government entity and sister concern of one of the top level companies but still unable to grab the good market share because top level management is strictly practicing the autocratic leadership style, for example if middle management people desire to hire one maintenance engineer for a project, they need approval from top management then only they can hire, even if middle management wants to buy some material above AED-5000, they need top management approval for that and process to get approval from higher management is very lengthy like there are seven committee members and each members signatures are essential on the purchase order which is not possible in one day or two so minimum lead time for one purchase order was almost one week which is not really healthy sign for a facilities management business, as client need quick fix to their asset. All the groups members agreed that the above mentioned scenarios result into the following:

- $\quad$ Increase in back log

- $\quad$ Bad repute of company

- Loss of business

- Un happy staff 
- $\quad$ Bad word of mouth

- $\quad$ Financial loss in terms of penalties

- Unhappy customers

However if we compare above stated scenario with another one where different styles of leadership being used, like in ABC facilities Management they are using democratic leadership style which empowers the middle management and allow them to take decisions according to the contract terms and condition, keeping in view that there should not be making any loss or damage to the company. This permits middle management to take immediate decision in order to resolve any kind of problem, clients will be even happier and satisfied when they will get good and quick services.

Based on the discussion analysis, following are the results of the democratic style of leadership.

- $\quad$ Employees feel more empowered

- $\quad$ Good repute of company

- $\quad$ Secure more business

- Good financial results

- Happy customers

\section{Leadership Style Used by Middle Level Management:}

In maintenance industry, middle management is closely working with the lower management and providing proper guidance to the lower level management because without that, the day to day operation cannot be possible so Middle Management using most of the leadership style mentioned in the aforementioned list in order to tackle the different situations on different point of times, but team leadership is most commonly used by the middle management in which they provide instructions, directions and guidance to a group to achieve the results.

There could be a disaster if middle management is practicing autocratic leadership style in routine matters but at the same time they have to use autocratic leadership style in case of emergencies, for example in case of fire, middle management has to provide direction to the lower level staff and ensure that lower level staff is only following your instructions in order to avoid any further major incident and to control the situation.

Variety in leadership styles is observed at middle level management, keeping the dynamics of the situation in view. This results in high motivation level in the subordinates. Overall reaction of the subordinates remains good only if you are using all above stated leadership styles on the right time and for the right event otherwise subordinates can disobey and refuse to work or the productivity will effect as they will be less interested in completing their 
tasks, majority agreed that to tackle the daily activities and to get maximum output it is recommended to go with the transformational leadership but some of them having different opinion and saying that autocratic is the best practice as then you can control your sub ordinates otherwise they will start leading you instead you lead them.

According to situational leadership models in general, Maintenance managers should adopt different leadership approaches depending on the situations that they encounter. Leadership competencies which work in one given situation may not be effective under different circumstances. The increasingly complex modern management environment demands for an effective approach to leadership, one that is adaptive to the different followers' situations. The appropriateness of a leadership style changes with change in the leadership environment. It is increasingly becoming mandatory that leaders in maintenance industry to remain flexible enough to engage leadership styles that will enhance the success of the project. It is also imperative to note that the leader-follower relationship determines the outcome of any particular task.

Some of the discussants had their view that situational leadership is based on both versatility and effectiveness. Four leadership approaches i.e. directing, coaching, facilitating \& delegating apply under the situational leadership model and are dependent on followers' job-related maturity and the same to be applied accordingly.

\section{Leadership Style Used by Lower Level Management:}

Engineers and supervisors are the front liners in the operations of maintenance industry and they directly deal with field technicians in order to execute the tasks. Leadership style being followed here is the mainly autocratic, that results in low motivation levels of the bottom level workers. Lower level management in maintenance industry look after the performance of employees working in the field tasks in managerial positions such as foreman, team leader, also called supervisory personnel or first level managers. The discussants reported following organizational pathologies resulting from the application of this autocratic style of leadership;

Low employee morale, lack of positive and productive organizational citizenship behaviour

More instrumentality in their day to day dealings with their coworkers, giving extra time to various services becomes a burden in that scenario, so the subordinates keep asking for the overtime payment. Due to the aforementioned organizational pathological conditions, the culture at lower level of management gets more employee centred rather than the organization centred. 


\section{Summary of Findings, Conclusions and Recommendations Summary of findings}

After having discussions with various officers from the selected firms in the maintenance industry, the researcher came to know that each level of management hierarchy is using different type of leadership style, for example, top level management is practicing autocratic leadership style and their subordinates are not really happy with it as they feel that top management should involve them in decision making and they should value their opinions as well. Middle level management is the one responsible for the operations, researcher discovered that middle level management using most of the leadership styles according to the situations, but mainly team leadership style was found to be in practise and their sub ordinates were found to be happy with that. Sometimes, middle management also using autocratic leadership style, depending on the situation. Lower management is mostly practicing autocratic leadership style in order to control the field staff but field staff were not found to be happy with all that.

\section{Conclusion}

Based on the findings of the study, following conclusions are drawn:

Top level management practicing autocratic style of leadership that is not yielding the desired results of higher motivation level and subordinates are also not really happy with it. Targets and being achieved but corporate citizenship feel is missing in the subordinates.

Middle level management is practicing almost all types of leadership styles but team leadership is most commonly used by middle level management, subordinates are generally happy with it.

Lower level management using autocratic leadership style in order to control the field staff; however field staff never felt happy with it as they feel bad when always engineers/supervisors imposing their decisions on them and being the work floor workers, their suggestions are not taken care of.

\section{Recommendations for Future Research}

Another study may be planned involving more companies to participate in the focus group discussion.

An empirical study may be designed to look into the corporate citizenship behavior of the employees working for the maintenance industry.

\section{Recommendations for the Maintenance Industry}

Keeping in view the findings of the study, it is strongly recommended that work floor maintenance staff to be properly listened to.

Top management should adopt democratic and participative leadership styles in order to create one unit spirit among various hierarchies. 
All management levels must make an effective use of more than one leadership styles such as democratic and transformational.

\section{References:}

1. Aarons, H. 2006. Transformational and transactional leadership: Association with attitudes toward evidence-based practice. Psychiatric services, 57(8), 1162-1169.

2. Barling et al. 2011. The typical leadership study: Assumptions, implications, and potential remedies. The Leadership Quarterly, 18(5), 435-446.

3. Bass, Y. 1985. Leadership and performance beyond expectations: Free Press; Collier Macmillan.

4. Burns, R. T. 2008. Impact of Organizational Citizenship Behavior on Managerial Effectiveness. Prabandhan: Indian Journal of Management, 9(2), 7-18.

5. Burns, U. 1978. The Leadership styles. Mc Graw Hill, NY

6. Chaudhary, W., Kuma, E. and Philip, R. 2015. Modern Management Principles. Prentice Hall, Inc. USA

7. David, J. and Kilner, K. 2014. Leadership styles used by senior medical leaders: Patterns, influences and implications for leadership development", Leadership in Health Services, Vol. 27 Iss: 4, pp.283 - 298

8. Given, D. S. 2008. Management Fundamentals. Thomsons Publishers, New Jersey

9. Gunderson, Y., Hellesoy, D. and Raeder. 2012. Transformational Leadership; Is this in Practice? Journal of social Behavior, Vol 3, No. 4 pp.332-337

10. Hersey, G. 2009. Is there some mantra for leadership? Journal of Social Sciences, Bangkok university, retrieved on Dec 01, 2016.

11. Mark, G. G. 1997. Dynamics of Leadership Phenomenon. An Unpublished Thesis in the Centre for Management studies, Devon, UK

12. Maslow, A. 1954. Maslow's hierarchy of needs. Available from interne t: http://www simply psychology. org/maslow. html. Retrieved on Dec 25, 2016.

13. Mauri, A. 2017. "Why leadership styles matter", Strategic Direction, Vol. 33 Iss: 1, pp.111-117

14. Naeem, et al. 2011. Pain Pleasure Theory of motivation. International Journal of Contemporary Research in Business. Retrieved on Dec 02, 2016.

15. Ogboanna, J. and Harris, D. 2016. Organizational Behavior. Text and Cases. Prentice Hall, Inc. 
16. Pedkoff, A. G. 2014. The Charismatic Leaders. Pretice Hall Inc. New Jersey

17. Sameul et al. 2007. Why study Leadership in Manufacturing. Journal of reliability Management. Vol 8, No. 4, pp 335-351

18. Smith, T. 1989. Modern Perspectives on Leadership and Motivation. Sage Publications, India

19. Toor, Z. and Afori, T. 2008. Leadership versus management: How they are different, and why. Leadership and Management in Engineering, 8(2), 61-71.

20. Vivek, S. A. 2016. Transactional and transformational leadership: A constructive/developmental analysis. Academy of Management review, 12(4), 648-657.

21. Wang et al . 2005. "Examining US principal perception of multiple leadership styles used to practice shared instructional leadership", Journal of Educational Administration, Vol. 54 Iss: 2, pp.152 - 172

22. Yahya, D. and Ebrahim, J. 2016. Leadership styles and their implications. Journal of Behavioral Sciences. Vol 5, No. 3, pp 445 460 